\title{
Isolating promoters from Corynebacterium ammoniagenes ATCC 6871 and application in CoA synthesis
}

\author{
Yingshuo Hou ${ }^{1,2}$, Siyu Chen ${ }^{1}$, Jianjun Wang ${ }^{1}$, Guizhen $\mathrm{Liu}^{3}$, Sheng $\mathrm{Wu}^{1 *}$ (D) and Yong Tao ${ }^{\text {** }}$
}

\begin{abstract}
Background: Corynebacterium ammoniagenes is an important industrial organism that is widely used to produce nucleotides and the potential for industrial production of coenzyme A by C. ammoniagenes ATCC 6871 has been shown. However, the yield of coenzyme A needs to be improved, and the available constitutive promoters are rather limited in this strain.

Results: In this study, 20 putative DNA promoters derived from genes with high transcription levels and 6 promoters from molecular chaperone genes were identified. To evaluate the activity of each promoter, red fluorescence protein (RFP) was used as a reporter. We successfully isolated a range of promoters with different activity levels, and among these a fragment derived from the upstream sequence of the 50 S ribosomal protein L21 $\left(P_{r p \mid 21}\right)$ exhibited the strongest activity among the 26 identified promoters. Furthermore, type III pantothenate kinase from Pseudomonas putida (PpcoaA) was overexpressed in C. ammoniagenes under the control of $\mathrm{P}_{\text {rpl21, }}$, CoA yield increased approximately 4.4 times.

Conclusions: This study provides a paradigm for rational isolation of promoters with different activities and their application in metabolic engineering. These promoters will enrich the available promoter toolkit for $C$. ammoniagenes and should be valuable in current platforms for metabolic engineering and synthetic biology for the optimization of pathways to extend the product spectrum or improve the productivity in C. ammoniagenes ATCC 6871 for industrial applications.
\end{abstract}

Keywords: Corynebacterium ammoniagenes, Transcriptome, Promoter, Coenzyme A

\section{Background}

Corynebacterium ammoniagenes (formerly known as Brevibacterium ammoniagenes) is a Gram-positive, nonpathogenic soil bacterium with high guanine-cytosine (GC) DNA content. Due to the divergent evolution of $C$. ammoniagenes, different strains are used to produce different metabolites. For example, C. ammoniagenes ATCC 6872 is used in the production of nucleotides and nucleosides [1], while C. ammoniagenes ATCC 6871 shows a relatively high synthesis capacity of coenzyme A (CoA), which is a ubiquitous and essential cofactor

\footnotetext{
* Correspondence: shengwu@im.ac.cn; taoyong@im.ac.cn

${ }^{1}$ CAS Key Laboratory of Microbial Physiological and Metabolic Engineering, Institute of Microbiology, Chinese Academy of Sciences, Beijing 100101, People's Republic of China

Full list of author information is available at the end of the article
}

found in all three domains of life and is involved in numerous metabolic pathways [2-4].

Sequencing of the $C$. ammoniagenes genome has helped to identify key enzymes for diverting carbon flow from metabolic pathways to other products $[5,6]$. However, a major breakthrough in genetic manipulation to precisely regulate the expression of individual biosynthetic genes is still in process. Progress in the manipulation of $C$. ammoniagenes genes has been achieved through the development of effective transformation protocols and cloning vectors [7]. Most vectors are based on the related C. glutamicum endogenous cryptic plasmids that have incorporated E. coli elements for transfer between the species [8-10]. Almost all these vectors have adopted $E$. coli promoters or C. ammoniagenes native promoters to express foreign proteins in $C$. ammoniagenes [11-13]. Although some of these

(c) The Author(s). 2019 Open Access This article is distributed under the terms of the Creative Commons Attribution 4.0 International License (http://creativecommons.org/licenses/by/4.0/), which permits unrestricted use, distribution, and 
promoters are active in $C$. ammoniagenes, the activities are quite low [14].

To efficiently engineer C. ammoniagenes, it is necessary to screen endogenous promoters. Paik and coworkers isolated 22 representative promoters from the genome of C. ammoniagenes ATCC 6872 and the activity of overexpressed chloramphenicol transacetylase from the strongest promoter IJ73 was $2.85 \mathrm{U}$ [7]. Similar studies have been performed by Park and coworkers, where they overexpressed the attenuator binding protein in C. ammoniagenes ATCC 6872 using the endogenous promoter CJ1 [15]. However, the above promoters have not been universally applied in $C$. ammoniagenes ATCC 6871 (see text), probably due to the divergent evolution of $C$. ammoniagenes genomes. For instance, the sequence identities of promoters IJ59 and IJ73 from C. ammoniagenes ATCC 6872 with the homologous promoters from C. ammoniagenes ATCC 6871 are 93 and $89 \%$, respectively. Therefore, due to the importance of $\mathrm{CoA}$, it is necessary to find promoters that are effective in C. ammoniagenes ATCC 6871.

Endogenous promoters can be obtained by genomic dissection or promoter trapping et.al [16]. Nonetheless, with the advent of genomics and transcriptomics, we can isolate promoters more rationally. Studies have shown that strong promoters are usually obtained from the promoters of essential genes whose transcription levels are presumed to be high and constant [17]. In addition, we found that some commonly-used strong promoters such as $\mathrm{P}_{\text {dnak }}$ in Gluconobacter oxydans and $\mathrm{P}_{\text {gro }}$ in Corynebacterium glutamicum are promoters of molecular chaperones $[18,19]$. In this study, the promoters for 20 genes with high transcription levels and 6 molecular chaperone-encoding genes are identified by bioinformatic methods and their activities were further examined experimentally. Among them, $\mathrm{P}_{r p l 21}$ was found to be the strongest promoter, which was used in the biosynthesis of CoA, increasing the yield by 4.4 times.

\section{Results}

Screening promoters and construction of probe-vector

C. ammoniagenes ATCC 6871 cells grown in LB medium and fermentation medium to the exponential phase $\left(\mathrm{OD}_{600 \mathrm{~nm}} \approx 2.0\right)$ were collected and sent to Mega genomics (Beijing, China) for RNA-seq. A total of 2411 genes were identified from the transcriptomic data. Considering that there are many cases in which genes are in the same operon, genetic loci analysis was performed and the results showed that 1508 genes in 547 operons were expressed. In general, genes in the same operons share a common promoter, so the first gene in each operon was selected. Thus, the total number of remaining genes was $1450(2411-1508+547)$. Transcription abundance analysis was used to select 71 genes with transcription levels in the top 100 in both RNA-seq profiles. Sequences upstream of the top 20 genes were predicted and scored using the online promoter prediction tool as described below. The annotations and RPKM values for these genes are shown in Table 1. A transcriptomic data analysis flow chart and the transcription levels of genes are shown in Fig. 1.

Previous studies have shown that most promoters of molecular chaperones exhibit high transcription levels in prokaryotes, so all 6 annotated molecular chaperones in the C. ammoniagenes ATCC 6871 genome (Accession Number: NZ_CP009244) (two GroEL, two DnaJ, one DnaK, and one Co-chaperone GroES) were identified and their promoters were predicted as described in materials and methods. The information of these genes and transcriptomic RPKM values are also listed in Table 1. By predicting the promoter regions, 26 promoters were constructed according to the rules described below and their corresponding RFP expression plasmids were named as pXMJ190- $\mathrm{P}_{n}$. The sequences of the 26 promoters are listed in Additional file 1: Table S3.

For a comprehensive comparison, two conserved homologous promoters CJ1 and IJ59 that are active in $C$. ammoniagenes ATCC 6872 were aligned against the genome of $C$. ammoniagenes ATCC 6871 by BLAST and were cloned into pXMJ190 to give pXMJ190-CJ1 and pXMJ190IJ59 [7, 15], respectively. Moreover, previous studies have shown promoters that work well in C. glutamicum may also be active in C. ammoniagenes [20]. Thus, a strong endogenous C. glutamicum promoter named $\mathrm{P}_{\text {gro }}$ (the promoter of groES gene) was cloned as pXMJ190-P gro [19]. In addition, the most widely used tac promoter and conserved SD sequence was also selected and cloned into pXMJ190 as pXMJ190- $\mathrm{P}_{\text {tac }}$ [21]. The pXMJ190 was used as negative control. A flowchart for construction of the probe vectors to identify promoters is shown in Fig. 2. All of the above constructed plasmids were validated by sequencing and then transformed into C. ammoniagenes ATCC 6871.

\section{Analysis and comparison of promoters in C. ammoniagenes ATCC 6871}

To analyze the activities of our cloned promoters, we first made a visual assessment of all C. ammoniagenes ATCC 6871 strains harboring pXMJ190, pXMJ190-CJ1, pXMJ190-

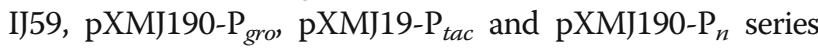
plasmids on LB plates containing $20 \mu \mathrm{g} / \mathrm{ml}$ chloramphenicol. Red fluorescence was observed by microscopy, with different intensities in different colonies, indicating that there was variable expression of RFP from the 26 putative promoters (Fig. 3a). Among these promoters, $\mathrm{P}_{\text {rpl21 }}, \mathrm{P}_{\text {rpl10, }}$, $\mathrm{P}_{\text {groELB }}$, and $\mathrm{P}_{\text {dnaK }}$ exhibited strong activity in C. ammoniagenes ATCC 6871, with $\mathrm{P}_{\text {rpl21 }}$ being the strongest promoter. The remaining promoters had very low or non-existent red fluorescence. 
Table 1 Identified molecular chaperone genes or those with high level expression from RNA-seq data

\begin{tabular}{|c|c|c|c|}
\hline Name & Downstream Product & Average RPKM & Score \\
\hline$P_{r r / A}$ & 235 ribosomal RNA & 988,873 & 0.99 \\
\hline$P_{r r l B}$ & $23 \mathrm{~S}$ ribosomal RNA & 913,696 & 0.97 \\
\hline$P_{t m r}$ & Transfer-messenger RNA & 853,640 & 0.96 \\
\hline$P_{f e r}$ & Ferritin & 46,832 & 0.92 \\
\hline$P_{\text {raiA }}$ & Ribosomal subunit interface protein & 44,446 & 0.91 \\
\hline$P_{\text {usp }}$ & Universal stress protein & 28,915 & 0.83 \\
\hline$P_{r p \mid 29}$ & $50 S$ ribosomal protein L29 & 24,596 & 0.89 \\
\hline$P_{\text {nat }}$ & $\mathrm{N}$-acetyltransferase & 18,830 & 0.96 \\
\hline$P_{a t p G}$ & FOF1 ATP synthase subunit gamma & 16,820 & 0.80 \\
\hline$P_{\text {tuf }}$ & Elongation factor Tu & 14,228 & 0.98 \\
\hline$P_{r p \mid 21}$ & $50 S$ ribosomal protein L21 & 13,153 & 0.81 \\
\hline$P_{f n t}$ & NarK/NasA family nitrate transporter & 12,650 & 0.94 \\
\hline$P_{g p d l}$ & Type I glyceraldehyde-3-phosphate dehydrogenase & 12,223 & 0.83 \\
\hline$P_{h f p}$ & Hemoglobin flavoprotein & 12,078 & 0.86 \\
\hline$P_{a c n}$ & Aconitate hydratase & 10,439 & 0.84 \\
\hline$P_{r p / 10}$ & 50 S ribosomal protein L10 & 10,398 & 1.00 \\
\hline$P_{a b m}$ & Antibiotic biosynthesis monooxygenase & 9935 & 0.73 \\
\hline$P_{\text {fball }}$ & Class II fructose-bisphosphate aldolase & 9740 & 0.77 \\
\hline$P_{r p l 11}$ & $50 S$ ribosomal protein L11 & 9473 & 0.82 \\
\hline$P_{s b p}$ & ABC transpoter, substrate-binding protein & 9120 & 0.99 \\
\hline$P_{\text {groELA }}$ & Molecular chaperone GroEL & 6594 & 0.89 \\
\hline$P_{\text {groELB }}$ & Molecular chaperone GroEL & 6261 & 0.87 \\
\hline$P_{\text {dnajA }}$ & Molecular chaperone DnaJ & 239 & 0.85 \\
\hline$P_{\text {dnasB }}$ & Molecular chaperone DnaJ & 703 & 0.87 \\
\hline P groEs & Co-chaperone GroES & 2215 & 1.00 \\
\hline$P_{\text {dnak }}$ & Molecular chaperone Dnak & 4523 & 0.98 \\
\hline
\end{tabular}

To quantify the activities of the cloned promoters, growth-normalized fluorescence intensities were measured using a microplate assay and the data are shown in Fig. $3 \mathrm{~b}$ and Additional file 1: Table S2, the results showed that we successfully isolated 20 endogenous promoters with different activities. Among the 20 promoters $\left(\mathrm{P}_{r r l A}-\mathrm{P}_{s b p}\right)$ from genes with high transcription levels, $\mathrm{P}_{t m r}, \mathrm{P}_{\text {nat }}, \mathrm{P}_{\text {atp }}, \mathrm{P}_{\text {gpdl }}, \mathrm{P}_{a c n}$ are essentially inactive, while $\mathrm{P}_{\text {groELA }}$ from the 6 molecular chaperone promoters was also inactive. Meanwhile, four strong promoters, including the $\mathrm{P}_{\text {rpl21 }}$ with 43,433 RFU/OD intensity and followed by $\mathrm{P}_{\text {dnaK }}(19,125 \mathrm{RFU} / \mathrm{OD}), \mathrm{P}_{\text {groELB }}$ (8166 RFU/ $\mathrm{OD})$ and $\mathrm{P}_{\text {rpl10 }}(6490 \mathrm{RFU} / \mathrm{OD})$ were identified whose fluorescence levels were consistent with those observed on plates. Thus, a range of promoters with different transcriptional activities, including four strong promoters, were identified and can be used directly in further applications. According to the obtained data, only two promoters $\left(\mathrm{P}_{r p l 21}\right.$ and $\left.\mathrm{P}_{r p l 10}\right)$ from the 20 genes with high levels of transcription had strong activities, while two promoters $\left(\mathrm{P}_{\text {groELB }}\right.$ and $\left.\mathrm{P}_{\text {dnaK }}\right)$ sourced from the six molecular chaperone genes exhibited relatively high activities, which may indicate that isolating promoters from molecular chaperones may be a more efficient strategy. Although most of the promoters identified from the RNA-seq profiles exhibited low level expression or were silent, the red fluorescence intensity of $\mathrm{P}_{r p l 21}$ was almost 2.3 times that of the highest promoter $\left(\mathrm{P}_{\text {dnaK }}\right)$ derived from upstream regions of the molecular chaperones. This suggests isolating promoters from genes with high transcription levels may yield strong promoters.

When it comes to the known promoters, the promoter CJ1 had some certain activity (4171 RFU/OD), the IJ59 (2866 RFU/OD) promoter had almost non activity, and the activity of $\mathrm{P}_{\text {gro }}$ (5872 RFU/OD) was slightly higher than the $\mathrm{P}_{t a c}$ (5683 RFU/OD) promoter but still lower than promoter $\mathrm{P}_{\text {rplio }}(6490 \mathrm{RFU} / \mathrm{OD})$. This demonstrates the promoters that work well in one species or homologous strains may not possess the same characteristics in another. 


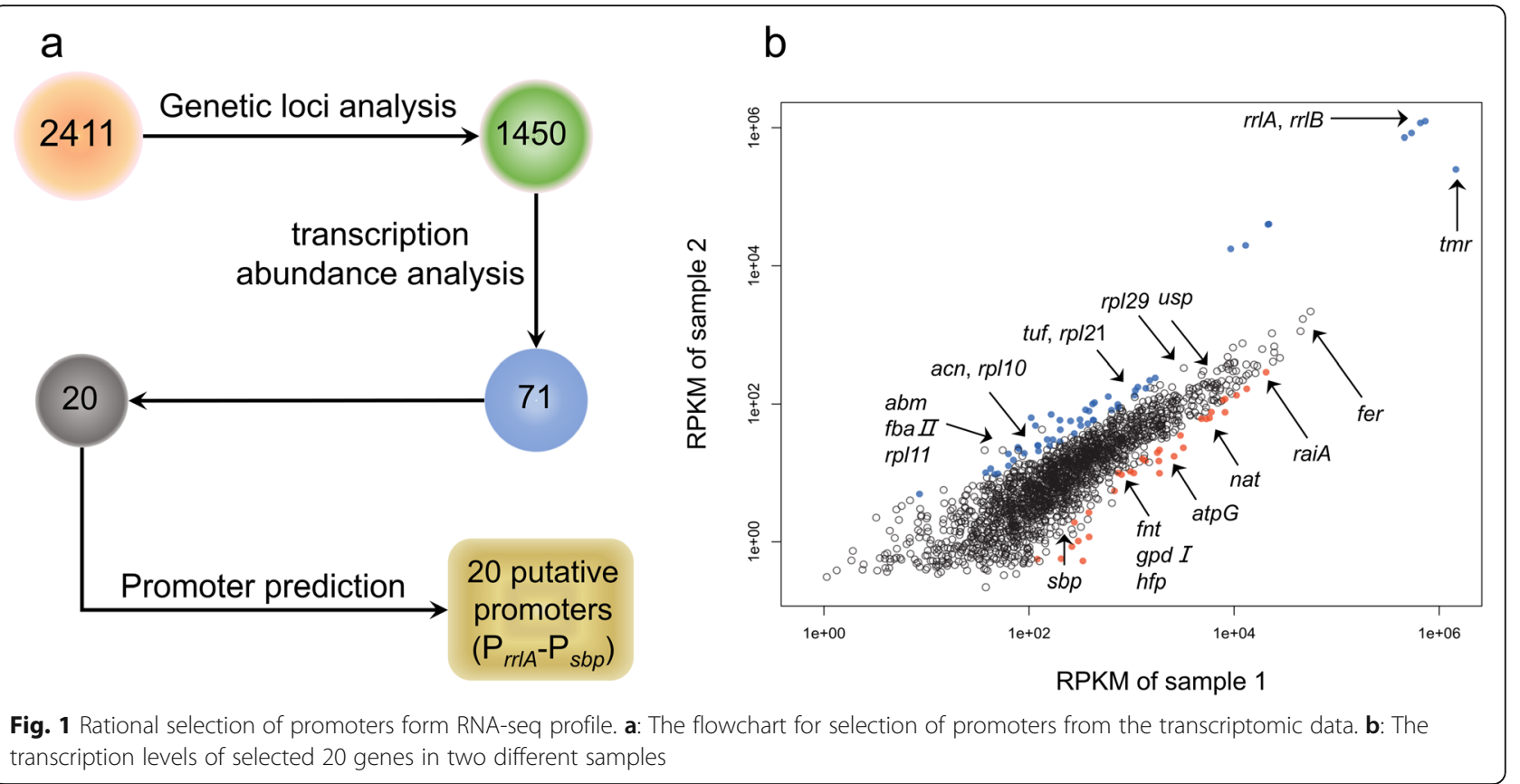

Application of $\mathrm{P}_{\mathrm{rpl21}}$ in $\mathrm{C}$. ammoniagenes for improving the production of $\mathrm{CoA}$

It has been reported that CoA, a ubiquitous and essential cofactor in biochemical reactions, can be produced by C. ammoniagenes ATCC 6871 [25]. In the CoA biosynthetic pathway, the committed step catalyzed by pantothenate kinase (coaA) is subject to feedback inhibition by CoA and acyl-CoAs [26]. Bacterial coaA proteins are categorized based on their amino acid sequences into three types, namely type I, II, and III. C. ammoniagenes carries a type I coaA which is highly regulated by $\mathrm{CoA}$ and its derivatives. In contrast, type II

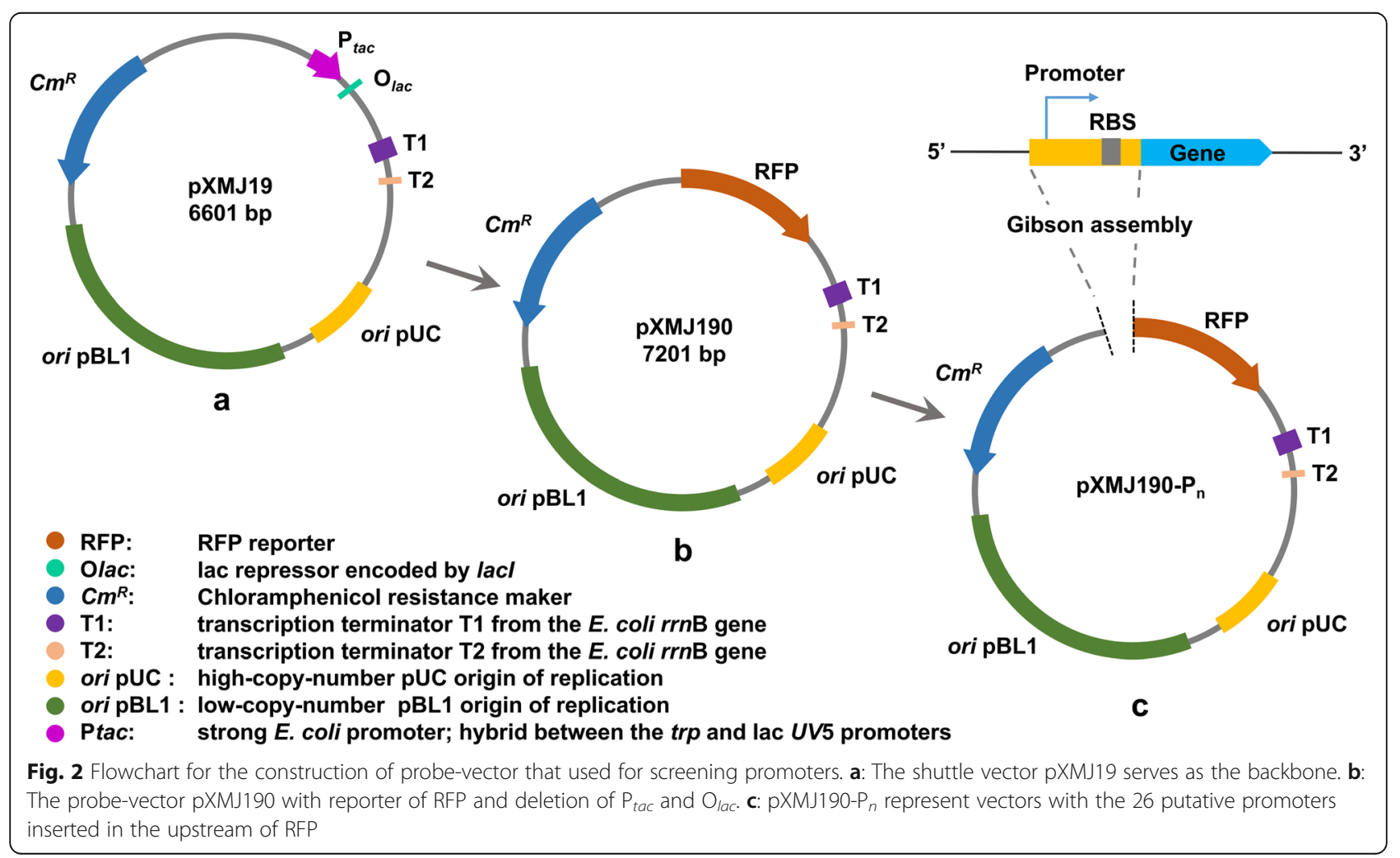




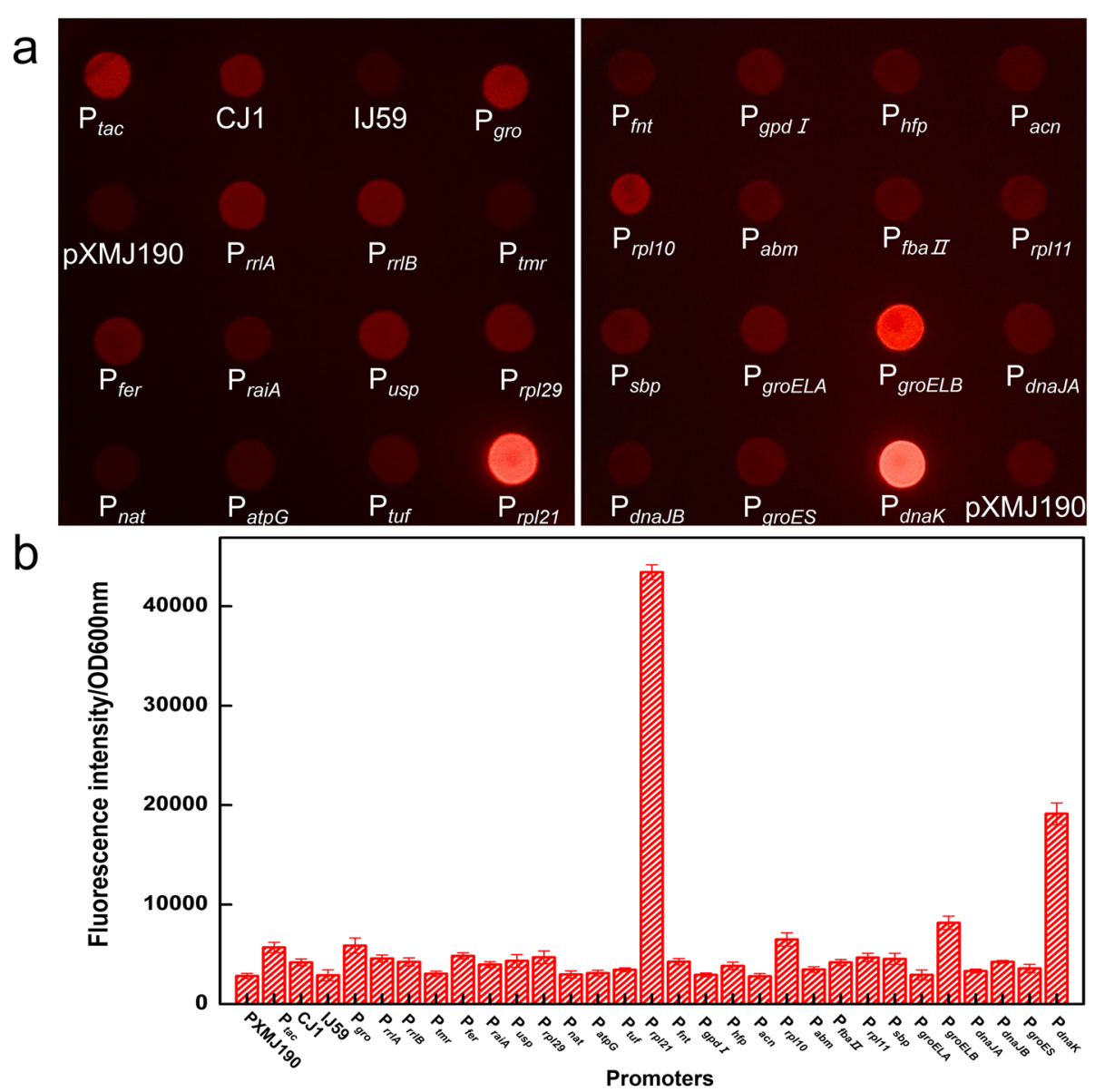

Fig. 3 Different activities of selected promoters. a: Observed red fluorescence of bacteria using a LUYOR-3430 stereo microscope with a fluorescence excitation source (LUYOR, USA) set at $501 \mathrm{~nm}$. b: Measured fluorescence intensities of bacteria using a Synergy H4 microplate reader. Cells were washed once with PBS ( $\mathrm{pH} 7.4$ ) and then resuspended in PBS ( $\mathrm{pH} 7.4$ ) at an $\mathrm{OD}_{600} \mathrm{~nm}$ of approximately 1.0. The excitation wavelength for RFP was set at $554 \mathrm{~nm}$ and emission was set at $586 \mathrm{~nm}$. Error bars show the standard deviation of three measurements

and III enzymes are insensitive to CoA and its thioesters $[27,28]$, therefore, in order to reduce feedback inhibition and increase the production of CoA, the type III pantothenate kinase from Pseudomonas putida (PpcoaA) was selected and overexpressed by the control of the strongest promoter $\mathrm{P}_{r p l 21}$ in C. ammoniagenes ATCC $6871[29,30]$.

Considering there are no direct enzyme assays for type III pantothenate kinase, RFP was co-expressed with PpcoaA. As shown in Fig. 4a, bright red fluorescence was observed in the tube with cells containing pXMJ190$\mathrm{P}_{r p l 21}$-PpcoaA-RFP, suggesting that RFP and PpcoaA were successfully co-expressed. By measuring the red fluorescence intensity, the strain harboring pXMJ190- $\mathrm{P}_{r p l 21^{-}}$ $P p$ coaA-RFP had up to $7560 \mathrm{RFU} / \mathrm{OD}$. This value was lower than that observed when RFP expressed alone under the control of $\mathrm{P}_{r p l 21}$, possibly due to the long distance from the transcription initiation site and the increased cellular burden caused by co-expression of two proteins. The expression of RFP and PpcoaA was also be observed by
SDS-PAGE. As shown in Fig. 4b, significant bands of approximately $27 \mathrm{kDa}$ and $32 \mathrm{kDa}$ were observed indicating that RFP and PpcoaA were overexpressed and that the $\mathrm{P}_{r p l 21}$ promoter functioned well in C. ammoniagenes. Furthermore, three crucial substrates (pantothenic acid (2 $\mathrm{mM})$, L-cysteine (2 $\mathrm{mM})$, ATP $(6 \mathrm{mM})$ ) were added to the reaction mixture containing a certain number of bacterial cells $\left(\mathrm{OD}_{600 \mathrm{~nm}} \approx 40\right)$ at $39^{\circ} \mathrm{C}$. Coenzyme A production increased to a satisfactory yield of approximately $315 \mathrm{U} / \mathrm{mL}$ in $6 \mathrm{~h}$ (Fig. 4c), which was almost 4.1 times higher than the same conditions without pXMJ190-P $\mathrm{P}_{\text {rpl21 }}$-PpcoaA-RFP in the cells $(76 \mathrm{U} / \mathrm{mL})$. The results indicated that $P p$ coaA was successfully overexpressed under the control of promoter $\mathrm{P}_{r p l 21}$ and increased the anabolic flow of CoA. To further improve the CoA production, the RFP gene was removed from the plasmid pXMJ190- $\mathrm{P}_{r p l 21}-P p$ coaA-RFP for eliminating the burden of RFP expression in cells. With the PpcoaA overexpressed alone in $C$. ammoniagenes, the CoA production was reached $332 \pm 13 \mathrm{U} / \mathrm{mL}$, which was 
a

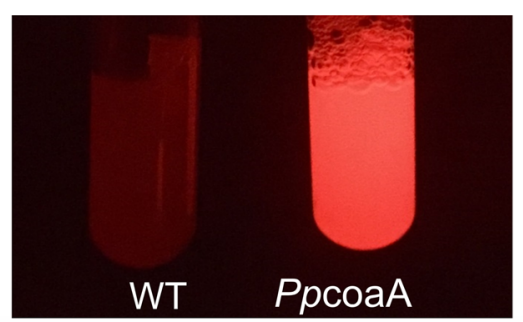

C

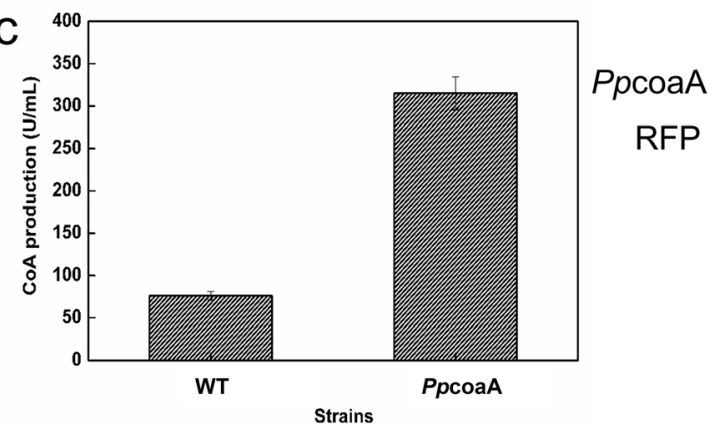

b

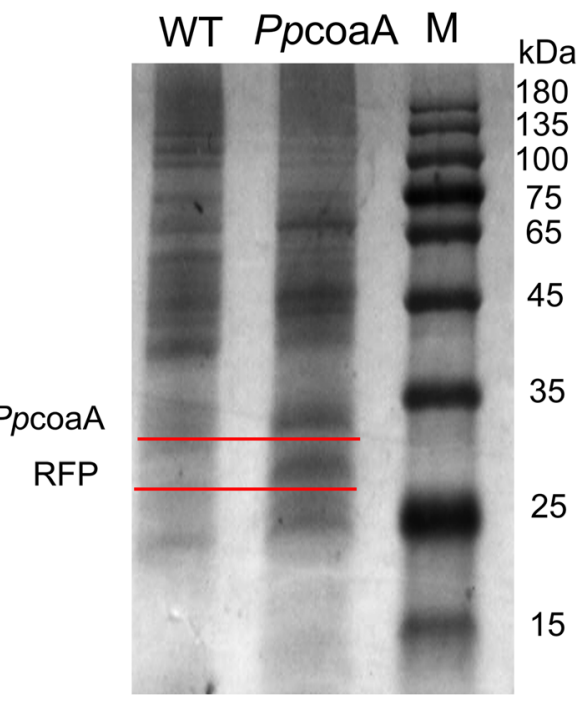

Fig. 4 Application of $P_{r p / 21}$ in C. ammoniagenes for improving the production of CoA. a: The comparison of fluorescence intensities between cells harboring pXMJ190-P rp/21-PpcoaA-RFP and wild type cells. b: SDS-PAGE analysis of RFP and PpcoaA co-expression in C. ammoniagenes. Samples were prepared with an equal concentration of cells, and $40 \mu \mathrm{g}$ of cell lysate were loaded per lane. Lane M: protein marker. c: The CoA production of cells harboring pXMJ190-P ${ }_{r p 121}$-PpcoaA-RFP and control. Error bars show the standard deviation of three measurements

slightly increased than the PpcoaA and RFP coexpressional system.

\section{Discussion}

C. ammoniagenes ATCC 6871 is a producer of CoA, however, its genetic operation has been rarely reported, and its industrial application potential still needs to be improved. In order to further increase the production of CoA, endogenous promoters from $C$. ammoniagenes ATCC 6871 were screened in this study. Firstly, 20 putative promoters based on genes with high transcription levels and 6 promoters upstream of molecular chaperones were identified and characterized for transcriptional activity by using RFP as the reporter gene. Among the 26 putative promoters, 20 with different transcriptional activities were isolated including 15 from the high transcription level genes and 5 from molecular chaperone genes. The output efficiency demonstrates that isolating promoters from molecular chaperones (5/ 6) might be a more efficient strategy than using RNAseq $(15 / 20)$. Therefore, isolating promoters from molecular chaperone genes is more effortless and costeffective than RNA-seq. These results may ascribe to that the RPKM values of the genes only represent the abundance of RNA and do not equivalent to its promoter activities, which might be caused by multiple factors, such as the codon usage of genes, copy numbers of genes, the half-lives of mRNA and limitations inherent in transcriptomics [22-24]. It thus, isolating promoters based on RNA-Seq requires further verification by experiments.

Nevertheless, we should note that the red fluorescence intensity of the highest promoter $\left(\mathrm{P}_{r p l 21}\right)$ identified from RNA-seq was almost 2.3 times than the highest promoter $\left(\mathrm{P}_{\text {dnaK }}\right)$ derived from molecular chaperone genes, so isolating promoters based on the genes transcriptional data may be more likely to yield promoters with highest activity. To our best knowledge, $\mathrm{P}_{r p l 21}$ from the upstream sequence of the $50 \mathrm{~S}$ ribosomal protein L21 is the strongest $C$. ammoniagenes ATCC 6871 promoter reported so far. The promoters obtained in this work will enrich the available promoter toolkit for C. ammoniagenes and should be valuable in current platforms for metabolic engineering and synthetic biology for the optimization of pathways to extend the product spectrum or improve the productivity in C. ammoniagenes ATCC 6871.

To further verify the capacity of $\mathrm{P}_{r p l 21}$, the key gene PpcoaA in the biosynthetic pathway of CoA was overexpressed in C. ammoniagenes ATCC 6871 with the aim of reducing the feedback inhibition and increasing the production of CoA. The CoA production of manipulated C. ammoniagenes was approximate 4.4 times to the control, which confirmed that PpcoaA overexpressed and functionalized successfully in C. ammoniagene. These results prove that the selected promoter for the overexpression of foreign genes in C. ammoniagenes could be used as an efficient tool for improving the yield of major 
products in C. ammoniagenes. However, eliminating the burden of co-expressing RFP only slightly increase the CoA production, possibly due to the undiscovered limitations exist in the CoA synthetic pathway. Thus, more efforts should be focus on the resolving of rate-limiting steps of CoA synthesis in C. ammoniagenes.

\section{Conclusions}

In summary, this study provides a rational strategy to isolate endogenous promoters from $C$. ammoniagenes ATCC 6871, which may be helpful in other similar scientific research. Through this strategy, we successfully isolated a range of promoters with different transcriptional activities and the strongest one was applied to improve the CoA production in C. ammoniagenes ATCC 6871, raising hope for further improving the industrial production level of $\mathrm{CoA}$.

\section{Methods}

\section{Bacterial strains, media, and growth conditions}

The C. ammoniagenes ATCC 6871 was purchased from China General Microbiological Culture Collection Center (CGMCC, Beijing, China). E. coli Top10 (Tsingke, Beijing, China) was cultivated in Luria-Bertani (LB) broth or on LB plates with $2 \%(\mathrm{w} / \mathrm{v})$ agar at $37^{\circ} \mathrm{C}$ as a host for transformation. C. ammoniagenes ATCC 6871 grown in NCM medium at $30^{\circ} \mathrm{C}$ was used as the transformation host for $E$. coli/Corynebacteria vectors used in this study. After transformation by electroporation (1.8 $\mathrm{kV})$, transformants were plated on BHIS plates with $20 \mu \mathrm{g} / \mathrm{mL}$ chloramphenicol at $30^{\circ} \mathrm{C}$. Fermentation medium (glucose $100 \mathrm{~g} / \mathrm{L}$, peptone $12 \mathrm{~g} / \mathrm{L}$, yeast powder $8 \mathrm{~g} / \mathrm{L}, \mathrm{MgSO}_{4} \cdot 7 \mathrm{H}_{2} \mathrm{O} 10 \mathrm{~g} / \mathrm{L}, \mathrm{KH}_{2} \mathrm{PO}_{4} 10 \mathrm{~g} / \mathrm{L}, \mathrm{K}_{2} \mathrm{HPO}_{4} 10$ $\mathrm{g} / \mathrm{L}$, urea $7 \mathrm{~g} / \mathrm{L}, \mathrm{pH} 7.5-7.8$ ) was used to cultivate strains producing CoA. Cultivation for expression analysis was performed in at least biological duplicates.

\section{Recombinant DNA techniques}

C. ammoniagenes genomic DNA was isolated using a genomic DNA isolation kit (Tiangen, Beijing, China). Kits for plasmid isolation, extraction of DNA from agarose gels and PCR product purification were also purchased from Tiangen (Beijing, China). I-5 $2 \times$ High-Fidelity Master Mix and Trelief ${ }^{\mathrm{m}}$ SoSoo Cloning Kit were purchased from Tsingke (Beijing, China) and used for routine molecular biology applications.

\section{Construction of probe-vector pXMJ190}

The shuttle vector pXMJ19 (a kind gift from Professor Dong, Fig. 2a) was used as the backbone for vectors constructed in this study. To eliminate interference from the promoter already present in pXMJ19, the tac promoter and lac operator were removed. A gene encoding red fluorescent protein (RFP) was inserted into the MCS to form a probe-vector named pXMJ190 (Fig. 2b). Gibson assembly was used to assemble DNA fragments upstream of the reporter gene $r f p$, resulting in seamless ligation between fragments and the probe-vector [31, 32].

\section{Genetic manipulation of $\mathrm{C}$. ammoniagenes}

To increase transformation efficiency, recipients were grown in $100 \mathrm{~mL}$ of $\mathrm{NCM}$ medium at $30^{\circ} \mathrm{C}$ until an $\mathrm{OD}_{600 \mathrm{~nm}}$ of approximately 1.0. Cells were incubated on ice for $20 \mathrm{~min}$ and harvested by centrifugation in a polypropylene tube at $4000 \mathrm{rpm}$ for $10 \mathrm{~min}$ at $4{ }^{\circ} \mathrm{C}$. After washing twice in cold distilled water and two washes in ice-cold $10 \%$ glycerol, cells were resuspended in $1 \mathrm{~mL}$ of $10 \%$ glycerol. For electroporation, $100 \mu \mathrm{L}$ of the freshly prepared electro-competent cells were mixed with $3 \mu \mathrm{L}$ plasmid $\left(50 \mathrm{ng} / \mu \mathrm{L}\right.$ in $\left.\mathrm{ddH}_{2} \mathrm{O}\right)$ in a cold sterile electroporation cuvette ( $1 \mathrm{~mm}$ electrode gap) and pulsed immediately with a MicroPulser electroporator (Bio-Rad Laboratories, Inc., Hercules, CA). The electroporator was usually set at a voltage of $1.8 \mathrm{kV}$. Cells were subsequently resuspended in $0.9 \mathrm{~mL}$ of BHIS, heated at $46^{\circ} \mathrm{C}$ for $6 \mathrm{~min}$ and withdrawn immediately for recovery by incubating for $3 \mathrm{~h}$ at $30^{\circ} \mathrm{C}$ and then plated for selection of transformants.

\section{Construction and analysis of selected promoters}

The transcriptional levels of genes can be estimated by Reads Per Kilobase per Million mapped reads (RPKM), so the genes were ranked by RPKM value based on transcriptional data from C. ammoniagenes and the top 20 genes were selected. All of the genes were identified from the genome and their promoters were predicted as below. Six annotated molecular chaperones in the genome were sorted and their promoters were predicted as outlined below. According to previous studies, the promoter-5'-UTR junction influences mRNA and protein levels $[23,33]$. Therefore, we integrated the corresponding 5'-UTR into each promoter.

Promoter sequences were predicted using the Neural Network Promoter Prediction online tool (http://www. fruitfly.org/seq_tools/promoter.html) [34]. The promoter prediction score threshold was set to 0.7 . Moreover, due to the possibility of tandem promoters, all eligible promoter sequences within $300 \mathrm{bp}$ upstream of the start codon were considered [35]. For correct transcription initiation, the complete "promoter" consisted of 5'-UTR, predicted promoter region and Shine-Dalgarno sequence, which typically correspond to the region $60 \mathrm{bp}$ upstream of a predicted promoter and $1 \mathrm{bp}$ upstream of the start codon. The $60 \mathrm{bp}$ extension upstream of the promoter accounts for potential UP-elements [36, 37].

Promoters were amplified from C. ammoniagenes ATCC 6871 and C. glutamicum ATCC 13032 genomic DNA with the corresponding primers. Oligonucleotide 
primers used in this work are listed in Additional file 1: Table S1. PCR products were ligated into the vector pXMJ190 using Gibson assembly as shown in Fig. 2c. All plasmids were constructed in E. coli TOP10 and then transformed into C. ammoniagenes ATCC 6871 for subsequent analysis.

\section{Fluorescence intensity assay}

To evaluate RFP expression under the control of the various promoters, $C$. ammoniagenes strains harboring various vectors were grown overnight on LB plates containing $20 \mu \mathrm{g} / \mathrm{ml}$ chloramphenicol. Fluorescence was observed using a LUYOR-3430 stereo microscope with a fluorescence excitation source (LUYOR, USA) set at 501 $\mathrm{nm}$ and matching lenses to detect RFP. Pictures were captured with a camera.

For more accurate comparisons, the fluorescence intensities of bacteria harboring different plasmids were measured using a Synergy H4 microplate reader (BioTek, USA). In order to exclude other interfering factors, harvested cells were washed once with PBS ( $\mathrm{pH}$ 7.4) and then resuspended in PBS ( $\mathrm{pH}$ 7.4) at an $\mathrm{OD}_{600} \mathrm{~nm}$ of approximately 1.0. The excitation wavelength for RFP was set at $554 \mathrm{~nm}$ and emission was set at $586 \mathrm{~nm}$. Fluorescence intensities were normalized by $\mathrm{OD}_{600 \mathrm{~nm}}$ and were used to indicate the activities of the promoters. Bacteria harboring pXMJ19- $\mathrm{P}_{t a c}$ were induced with $1 \mathrm{mM}$ IPTG.

\section{Construction of the recombinant plasmid pXMJ190- $\mathrm{P}_{\mathrm{rpl21}}{ }^{-}$ PpcoaA-RFP}

To further examine the function of the isolated promoters, a type III pantothenate kinase from $P$. putida KT2440 (Pp coA) and RFP were co-expressed under the control of the strongest promoter $\mathrm{P}_{r p l 21}$. The PpcoaA gene was amplified by PCR from the genomic DNA of $P$. putida KT 2440, and the Shine-Dalgarno sequence for translation of RFP was calculated using the RBS calculator online tool (https://www.denovodna.com/software/). All primers used in this section are listed in Additional file 1: Table S1. The recombinant plasmid pXMJ190$\mathrm{P}_{r p l 21}$-PpcoaA-RFP was constructed with Gibson assembly and positive colonies were confirmed by DNA sequencing (Tsingke, China). Recombinant plasmids were transformed into C. ammoniagenes ATCC 6871 for further experiments.

\section{SDS-PAGE analysis}

C. ammoniagenes strains were precultured in $10 \mathrm{~mL} \mathrm{LB}$ medium at $30^{\circ} \mathrm{C}$ and shaken at $220 \mathrm{rpm}$ for $24 \mathrm{~h}$. Ten percent of the culture was inoculated in a $250 \mathrm{~mL}$ shake flask containing $100 \mathrm{~mL}$ fermentation medium. After $24 \mathrm{~h}$ cultivation, cell samples were harvested by centrifugation at $12,000 \mathrm{rpm}$ for $10 \mathrm{~min}$. Forty micrograms of cell lysate were loaded per lane. The PpcoaA and RFP expression was analyzed by $15 \%(\mathrm{v} / \mathrm{w})$ polyacrylamide gel electrophoresis (PAGE) with cell-free extract under denaturing conditions. Mini-Protean III Electrophoresis System (BioRad, USA) was utilized to perform the operation. Coomassie Brilliant Blue R-250 (0.2\%, w/v) was utilized to stain protein on the gel.

\section{Analysis of CoA production}

Coenzyme A content was determined according to the modified phosphotransacetylase method [38, 39]. All reagents were purchased from National Institutes for Food and Drug Control. Briefly, $3.0 \mathrm{~mL}$ of Tris buffer (pH 7.6), $0.1 \mathrm{~mL}$ of acetyl phosphate dilithium salt $(15.2 \mathrm{~g} / \mathrm{L})$ and 0.1 $\mathrm{mL}$ of the test solution were added into a $1 \mathrm{~cm}$ cuvette and mixed. Absorbance at $233 \mathrm{~nm}$ was recorded as $\mathrm{E}_{0}$; and then $0.01 \mathrm{~mL}$ of the phosphotransacetylase $(30-40 \mathrm{U} / \mathrm{mL})$ solution was added, mixed well and the highest absorbance within 3 to 5 min was taken as $E_{1}$. Finally, another $0.01 \mathrm{~mL}$ of phosphotransacetylase solution was added, mixed well and the absorbance was read as $E_{2}$. The number of CoA units per milliliter was calculated as $\mathrm{U}=\left(2 \mathrm{E}_{1}-\mathrm{E}_{0}-\mathrm{E}_{2}\right) \times$ $5.55 \times 413$.

\section{Supplementary information}

Supplementary information accompanies this paper at https://doi.org/10. 1186/s12896-019-0568-9.

Additional file 1: Table S1. Primer sequences used in this study. Table S2. Comparison of different promoter activities in C. ammoniagenes ATCC 6871. Table S3. The sequences of identified promoters.

Abbreviations

CoA: coenzyme A; IPTG: Isopropyl $\beta-D-1$-thiogalactopyranoside

Acknowledgements

We are grateful to Professor Zhiyang Dong (Institute of Microbiology, Chinese Academy of Sciences, China) for generously providing the plasmid pXMJ19. This work was supported by Grant from National Natural Science Foundation of China (31570077 to S.W.).

Authors' contributions

YH, SW, YT designed all the experiments; $Y H$ and SC carried out the experiments, $\mathrm{YH}$ organized and interpreted the data, and drafted the manuscript. JW, GL, SW and YT contributed to discussion, revised and corrected the manuscript. All authors read and approved the final manuscript.

\section{Funding}

This study was funded by National Natural Science Foundation of China (31570077). The funding body did not play any role in the design, execution, analysis, and interpretations of data or in writing the manuscript.

Availability of data and materials

All data generated or analyzed during this study are included in this manuscript and the Additional files associated with it.

Ethics approval and consent to participate Not applicable.

Consent for publication

Not applicable. 


\section{Competing interests}

The authors declare that they have no competing interests.

\section{Author details}

'CAS Key Laboratory of Microbial Physiological and Metabolic Engineering, Institute of Microbiology, Chinese Academy of Sciences, Beijing 100101, People's Republic of China. ${ }^{2}$ University of Chinese Academy of Sciences, Beijing 100101, People's Republic of China. ${ }^{3}$ Kaiping Genuine Biochemical Pharmaceutical Co. Ltd, Kaiping, People's Republic of China.

Received: 4 June 2019 Accepted: 10 October 2019

Published online: 12 November 2019

\section{References}

1. Kamada N, Yasuhara A, Takano Y, Nakano T, Ikeda M. Effect of transketolase modifications on carbon flow to the purine-nucleotide pathway in Corynebacterium ammoniagenes. Appl Microbiol Biotechnol. 2001;56(5-6):710-7.

2. Liu L, Yang H, Shin HD, Li J, Du G, Chen J. Recent advances in recombinant protein expression by Corynebacterium, Brevibacterium, and Streptomyces: from transcription and translation regulation to secretion pathway selection. Appl Microbiol Biotechnol. 2013;97(22):9597-608.

3. Shimosaka T, Tomita H, Atomi H. Regulation of coenzyme A biosynthesis in the Hyperthermophilic bacterium Thermotoga maritima. J Bacteriol. 2016; 198(14):1993-2000.

4. Sibon OC, Strauss E. Coenzyme A. to make it or uptake it? Nat Rev Mol Cell Biol. 2016;17(10):605-6.

5. Fujio T, Maruyama A. Enzymatic production of pyrimidine nucleotides using Corynebacterium ammoniagenes cells and recombinant Escherichia coli cells: enzymatic production of CDP-choline from orotic acid and choline chloride (part I). Biosci Biotechnol Biochem. 1997;61(6):956-9.

6. Ishige T, Honda K, Shimizu S. Whole organism biocatalysis. Curr Opin Chem Biol. 2005;9(2):174-80.

7. Paik JE, Lee BR. I isolation of transcription initiation signals from Corynebacterium ammoniagenes and comparison of their gene expression levels in C. ammoniagenes and Escherichia coli. Biotechnol Lett. 2003;25(16): 1311-6.

8. Ozaki A, Katsumata R, Oka T, Furuya A. Transfection of Corynebacterium glutamicum with temperate phage (CG1. Agric Biol Chem. 1984;48(10): 2597-601.

9. Santamaria R, Gil JA, Mesas JM, Martin JF. Characterization of an endogenous plasmid and development of cloning vectors and a transformation system in Brevibacterium lactofermentum. J Gen Microbiol. 1984;130(9):2237-46

10. Sonnen H, Thierbach G, Kautz S, Kalinowski J, Schneider J, Puhler A, Kutzner HJ. Characterization of pGA1, a new plasmid from Corynebacterium glutamicum LP-6. Gene. 1991;107(1):69-74.

11. Billman-Jacobe $H$, Wang L, Kortt A, Stewart D, Radford A. Expression and secretion of heterologous proteases by Corynebacterium glutamicum. Appl Environ Microbiol. 1995;61(4):1610-3.

12. Salim K, Haedens V, Content J, Leblon G, Huygen K. Heterologous expression of the Mycobacterium tuberculosis gene encoding antigen 85A in Corynebacterium glutamicum. Appl Environ Microbiol. 1997;63(11):4392-400.

13. Tsuchiya M, Morinaga Y. Genetic control Systems of Escherichia Coli can Confer Inducible Expression of cloned genes in Coryneform Bacteria. Nat Biotechnol. 1988:6(4):428-30.

14. Lee SM, Lee JY, Park KJ, Park JS, Ha UH, Kim Y, Lee HS. The regulator RamA influences cmytA transcription and cell morphology of Corynebacterium ammoniagenes. Curr Microbiol. 2010;61(2):92-100.

15. Park JU, Jo JH, Kim YJ, Chung SS, Lee JH, Lee HH. Construction of heatinducible expression vector of Corynebacterium glutamicum and C. ammoniagenes: fusion of lambda operator with promoters isolated from C. ammoniagenes. J Microbiol Biotechnol. 2008;18(4):639-47.

16. Deaner M, Alper HS. Promoter and terminator discovery and engineering. Adv Biochem Eng Biot. 2018;162:21-44.

17. Li S, Wang J, Li X, Yin S, Wang W, Yang K. Genome-wide identification and evaluation of constitutive promoters in streptomycetes. Microb Cell Fact. 2015;14:172

18. Hu Y, Wan H, Li J, Zhou J. Enhanced production of L-sorbose in an industrial Gluconobacter oxydans strain by identification of a strong promoter based on proteomics analysis. J Ind Microbiol Biot. 2015;42(7): 1039-47.
19. Schafer A, Schwarzer A, Kalinowski J, Puhler A. Cloning and characterization of a DNA region encoding a stress-sensitive restriction system from Corynebacterium glutamicum ATCC 13032 and analysis of its role in intergeneric conjugation with Escherichia coli. J Bacteriol. 1994;176(23):7309-19.

20. Itaya H, Kikuchi Y. Secretion of Streptomyces mobaraensis protransglutaminase by coryneform bacteria. Appl Microbiol Biotechnol. 2008; 78(4):621-5.

21. Jakoby $M$, Kramer $R$, Burkovski A. Nitrogen regulation in Corynebacterium glutamicum: isolation of genes involved and biochemical characterization of corresponding proteins. FEMS Microbiol Lett. 1999;173(2):303-10.

22. Jacobs $E$, Mills JD, Janitz $M$. The role of RNA structure in posttranscriptional regulation of gene expression. J Genet Genomics. 2012;39(10):535-43.

23. Mutalik VK, Guimaraes JC, Cambray G, Mai QA, Christoffersen MJ, Martin L, Yu A, Lam C, Rodriguez C, Bennett G, Keasling JD, Endy D, Arkin AP. Quantitative estimation of activity and quality for collections of functional genetic elements. Nat Methods. 2013;10(4):347-53.

24. Rytter JV, Helmark S, Chen J, Lezyk MJ, Solem C, Jensen PR. Synthetic promoter libraries for Corynebacterium glutamicum. Appl Microbiol Biotechnol. 2014;98(6):2617-23.

25. Shimizu S, Esumi A, Komaki R, Yamada H. Production of coenzyme A by a mutant of Brevibacterium ammoniagenes resistant to Oxypantetheine. Appl Environ Microbiol. 1984:48(6):1118-22.

26. Vallari DS, Jackowski S, Rock CO. Regulation of pantothenate kinase by coenzyme A and its thioesters. J Biol Chem. 1987;262(6):2468-71.

27. Brand LA, Strauss E. Characterization of a new pantothenate kinase isoform from Helicobacter pylori. J Biol Chem. 2005:280(21):20185-8.

28. Leonardi R, Chohnan S, Zhang YM, Virga KG, Lee RE, Rock CO, Jackowski S. A pantothenate kinase from Staphylococcus aureus refractory to feedback regulation by coenzyme A. J Biol Chem. 2005;280(5):3314-22.

29. Ogata Y, Chohnan S. Prokaryotic type III pantothenate kinase enhances coenzyme A biosynthesis in Escherichia coli. J Gen Appl Microbiol. 2015; 61(6):266-9.

30. Ogata Y, Katoh H, Asayama M, Chohnan S. Role of prokaryotic type I and III pantothenate kinases in the coenzyme A biosynthetic pathway of Bacillus subtilis. Can J Microbiol. 2014:60(5):297-305.

31. Engler C, Kandzia R, Marillonnet S. A one pot, one step, precision cloning method with high throughput capability. PLoS One. 2008;3(11):e3647.

32. Gibson DG, Young L, Chuang RY, Venter JC, Hutchison CA III, Smith HO. Enzymatic assembly of DNA molecules up to several hundred kilobases. Nat Methods. 2009;6(5):343-5.

33. Kosuri S, Goodman DB, Cambray G, Mutalik VK, Gao Y, Arkin AP, Endy D, Church GM. Composability of regulatory sequences controlling transcription and translation in Escherichia coli. Proc Natl Acad Sci U S A. 2013;110(34): 14024-9.

34. Reese MG. Application of a time-delay neural network to promoter annotation in the Drosophila melanogaster genome. Comput Chem. 2001; 26(1):51-6.

35. Ming YM, Wei ZW, Lin CY, Sheng GY. Development of a Bacillus subtilis expression system using the improved Pglv promoter. Microb Cell Factories. 2010:9:55

36. Estrem ST, Gaal T, Ross W, Gourse RL. Identification of an UP element consensus sequence for bacterial promoters. Proc Natl Acad Sci U S A. 1998; 95(17):9761-6.

37. Zhao Z, Liu X, Zhang W, Yang Y, Dai X, Bai Z. Construction of genetic parts from the Corynebacterium glutamicum genome with high expression activities. Biotechnol Lett. 2016;38(12):2119-26.

38. Stadtman ER, Novelli GD, Lipmann F. Coenzyme A function in and acetyl transfer by the phosphotransacetylase system. J Biol Chem. 1951;191(1):365-76

39. Tsuchiya Y, Pham U, Gout I. Methods for measuring CoA and CoA derivatives in biological samples. Biochem Soc Trans. 2014;42(4):1107-11.

\section{Publisher's Note}

Springer Nature remains neutral with regard to jurisdictional claims in published maps and institutional affiliations. 